\title{
Human centered design education-Design Education in the new era
}

\author{
Boxin $\mathrm{Xiao}^{1 *}$ \\ ${ }^{1}$ Department of industrial design, Xi' an University of Technology, Xi' an, Shaanxi, 710054, China
}

\begin{abstract}
China's design education has not developed as fast and well as the economy. Instead, problems such as blindly imitating foreign design education, failing to deeply develop students' potential, and failing to develop students' design thinking have emerged. Since the industrial revolution, design has been repeatedly defined and revised at different times. Similarly, design education needs to be constantly discussed in combination with the country, era, culture and population. Colleges and universities should not train "hand-drawn/modeling machines", but let every student find himself and know human beings; Have empathy for others, insight into the environment, and confidence to use your strengths. Because design and education have to deal with people, it means that they don't have to follow a process, summarize a method to get the truth. Teachers, students and designers have been involved in adjusting cognition to find more responsive answers to this era.
\end{abstract}

\section{Introduction}

The tactile paving raised in Japanese subway tiles has now become the exclusive channel used by "phubbers" to

direct the way, revealing the influence of environment and objects on people and the unstable relationship with peoples[1].

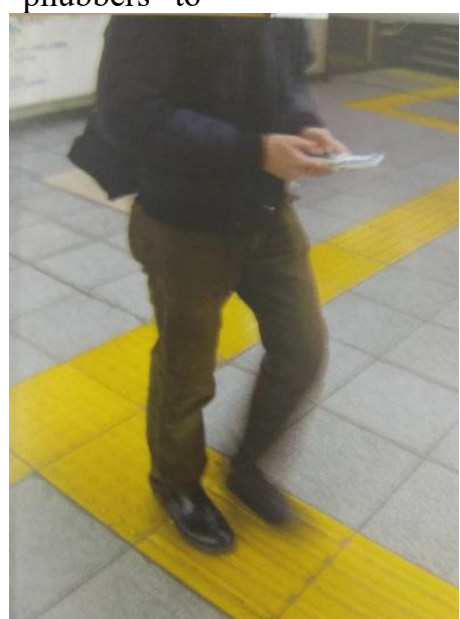

Figure 1. The tactile paving in Japanese subway station[1]

That is to say, there is no such thing as a fixed design product, nor a design philosophy that is once and for all. We need to constantly find appropriate answers for changing situations. This is true of design, and it is also true of design education.
Both design and education are no small topic, especially when it comes to their current problems and drawbacks. Objectively speaking, China has a large population base, and colleges and universities are expanding enrollment, including a large number of design students. 
Table 1. The number of universities offering industrial design majors in China[2]

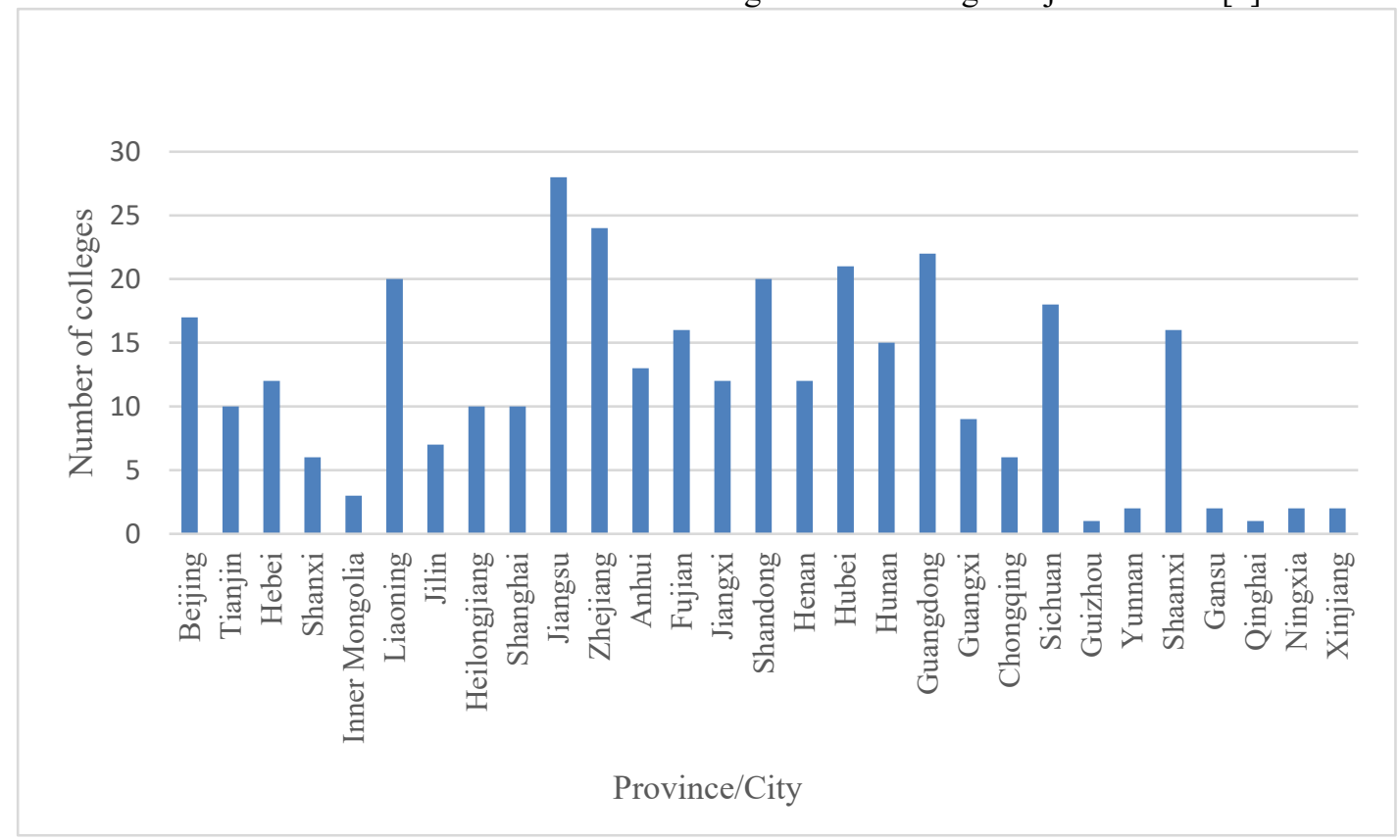

By the end of 2017, China had 337 universities offering industrial design majors, covering all provinces except Xizang and Hainan. It doesn't matter whether the society can digest so many design students. First of all, to become a designer, one often needs to master a certain degree of "basic skills", such as hand-drawing, modeling, rendering and other tools to express one's ideas in one's mind and communicate with others in some form. However, according to the survey, nearly 90 percent of engineering students have not received design education before entering the university, and they do not know enough about the design major.

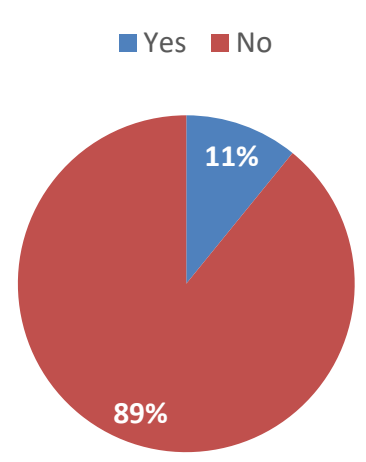

Figure 2. The situation of Engineering students' design education before enter college[3]

And a large number of students in the "diluted" teacher supervision is difficult to strict requirements themselves, unable to adhere to daily training, addicted to the network, love and other things, they know little about design techniques, can not skillfully use. In addition, for the students who have been in the "cramming" education for more than a decade after the college entrance examination, it is particularly important to learn the design thinking of innovative creativity, empathy for the needs of others, attention to the details of life and insight into the nature of problems.

However, at present, higher education still only uses the "Bauhaus" shell (color, composition), but loses its soul (creation, responsibility). Take industrial design, which is dominated by engineering students, as an example. After four years of education, a large number of students are still unable to skillfully complete handdrawn expression of products and computer modeling and rendering of complex products, not to mention design thinking and innovation ability. When entering the work, often within a few years will not be engaged in the design industry. Design education has fallen to the lowest "cost effective" category of higher education in China[4].

\section{What design is -- each generation has to answer}

"There is nothing worth thinking about that has not been thought about; All we have to do is try to rethink it." -Goethe

Design is certainly something to think about, and Nigel Cross believes that design should be developed as 
a strong independent discipline, rather than being defined as a branch of science or art[5]. Therefore, since the beginning of the industrial revolution, design has been constantly rethought and defined along with the changing "situation". Design, for example, is a meaningful and intuitive effort to achieve meaningful order[6]. We all agree that design is not narcissistic, its existence in society has its value and significance. But what is the real meaning? Is what was accepted 100 years ago still as important today?

The Modernist master Le Corbusier once said: "The style of architecture is like the feathers on a woman's hat. It is not important. It looks good but it lacks real value[7]. And since the 1980s, when the Memphis team led by Ettore Sottsass began the Memphis movement, other aspects of design have resurfaced: functional as well as emotional. At almost the same time, Hartmut Esslinger also initiated "form follows passion", combining excellent and advanced science and technology with human needs and emotions, and defining products in terms of cultural passion and practicality[8].

Modernist design transforms the goal of serving the powerful for thousands of years into serving the people, and post-Modernist design also echoes the social value orientation of advocating culture and seeking the value of human existence. Although it is all "for the sake of people", the reason why there is such a big difference is that when the question of survival is the main contradiction of the masses, people accept the single value of Modernism, but the people of rich society need more than just survival[9]. In addition, the world is still in turmoil after the two World Wars; the cold war between the US and the Soviet Union; the Chernobyl incident and so on make people start to rethink the idea that whether only technology and machine are supreme. After the Modernist design with the original intention of "serving the people" evolved into the "Internationalism" style, it began to pursue the simplicity of form, antidecoration, and highly rational characteristics, ignoring the functionality and the simplicity originally intended to reduce the cost. In this context, the post-Modernism design is the correction of Modernism design.

The design is to "define and manage limits", meet "non-negotiable" limits, such as chair load bearing, and optimize "negotiable" limits, such as chair cost[10]. It can be seen that each era has its own special "limit", and the standard of definition can not be "accomplish the whole task at one stroke". Dai Sato gave a romantic definition of design: "The ultimate goal of design is to make everyone related to the project feel happy[11]." It means taking the client's needs as your own, not missing any seemingly ordinary thing in your life, observing and analyzing it, finding inspiration, and coming up with new ideas to solve the problem at hand[12].It can be seen that design is about the coordination and resolution of contradictions among people, things and environment. Therefore, designers of each era are required to provide new supplement or correction to the problems that need to be solved in his era (new generation of people, new things, changing natural environment).

\section{What is education -- to cultivate people}

Some people compare the current education to the peas in Cinderella[13]. Cinderella wanted to go to the prince's ball, but her stepmother threw a pot of peas in the ashes and asked Cinderella to pick them up before she could go. There was no point in picking up the peas, but it was enough to stop Cinderella from doing something worthwhile -- going to the prince's ball. Chinese students have been receiving spoon-feeding education for a long time, the cultivation of ability and personality has been neglected. Problems such as poor learning consciousness, poor self-regulation and poor self-restraint have occurred in the stage of higher education[14].

So what is the value of education, is it a test? Is to take an examination of a good university, get a good job? Get a good college, get a good job, get a good marriage, and then let our next generation copy our life?

Shanghai Jiuqian, a non-profit education agency, thinks the key to education lies in what kind of educational soil we provide to these children, what kind of world we let them see, and what kind of confidence we let them have in their hearts[15]. In the documentary "childhood in another land", primary education in northern Europe tries not to set tests and encourages students to discover, affirm and develop their strengths. There is a "growth tree" on the wall of the classroom. Maybe the student is good at Math, or good at Languages, or not good at every subject, but he is brave and has leadership, which is recognized.

Education should enable everyone to find themselves, each person's dream is really related to his own things, not some adults give them the dream, such as some "success" road. The meaning of education is to let different individuals understand their own differences, find the power to make progress, become more tolerant, and be able to understand themselves, the world and human beings from a higher perspective[15]. Education is to protect the freedom of students' nature, stimulate their natural potential, let students find themselves, let students become themselves, so that students can have the courage to live according to their own will, have the energy to explore[13].

\section{Design education}

The education of design is not to teach those students inside the walls how to draw and how to be regulated, but to teach them how to think and create a life[16]. More than any other subject, design education needs to be tailored to the students and guided by the students rather than forced to do what the teachers like. "You can't impose high art on everyone," says Robert Venturi. "... We should adapt to different cultural tastes. It's Beethoven, it's the beatles, it's the streets of Las Vegas, it's the green Spaces of New England[7]." The "gun-like thinking" in interactive design is also applicable to design education. As a designer (teacher), one must accurately see the needs of users (students) and then "shoot" accurately. "Participatory design", which has been applied in design projects in recent years, can serve as an inspiration for the enlightenment course of design thinking. Participatory design is a human work system in 
order to understand and design the democratization process, all stakeholders have equal opportunities to them to be used in the discussion of the design of the product. In participatory design, designers and researchers see themselves as facilitators -- trying to encourage users to understand their own problems and generate ideas to address this need[17]. Teachers and students work together to solve the problem of students understanding themselves. Students themselves are the first products they design and the first problem they solve.

\section{Conclusion}

Low-level education presents a set of closed and established knowledge. At a high level, both teachers and students have legitimate reasons to explore knowledge together. -- Wilhelm Von Humboldt[8].

In the movie Looking Up, the father tells his son that life is like shooting an arrow, and dreams are like a target. If there is no target, then every archery is meaningless. Similarly, in design education, we still have to constantly explore, adjust and ask ourselves: what kind of students will our education produce? What qualities do we want our students to have? Found the "target", after the means of training, teaching mode and so on have meaning.

Design needs to make appropriate responses to different environments, people and different things in different times. That is to say that the current design education also needs to provide answers to meet the new needs of students and society.

\section{References}

1. Fukasawa, N. (2016) Naoto Fukasawa. Zhejiang People's Publishing House, Zhejiang, China.

2. The sun the university entrance exam. (2017) Industrial design professional knowledge base. https://gaokao.chsi.com.cn/zyk/zybk/specialityDetai 1.action?specialityId $=73384212$

3. Xu, J. (2017) The Study of Product Design "Progressive Project-Based Learning" Teaching Model. Jiangnan University

4. Tong, H.M. (2008) Expansion \& DeteriorateThe Contemporary Crisis of Design Education in China. Art \& Design, 04: 56-63.

5. Cross, N. (2013) Designerly ways of knowing. Huazhong University of Science \& Technology Press. Wuhan, China.

6. Papanek, P. (2012) Design for the real world. CITIC Press. Beijing, China.

7. Sudjic, D. (2015) The Language of Things. GUANGXI NORMAL UNIVERSITY PRESS (GROUP) . Guilin, China.

8. Zong, M.M., WANG, R.Y. (2015) FRAGMENTS OF HISTORY - - A GLIMPSE TO THE FORMING OF THOUGHTS ON GERMAN INDUSTRIAL DESIGN. Design, 01: 50-59.

9. Han, H.J. (2008) Discussion on Humanism in Modern Design Abstract. Soochow University.

10. Wang, S.Z. (2002) A HISTORY OF MODERN DESIGN. CHINA YOUTH PUBLISHING GROUP. Beijing, China
11. Sato, D. (2017) Design subtraction of DaiSato. Huazhong University of Science \& Technology Press. Wuhan, China.

12. Sato, D. (2016) Solve problems with design. Beijing Times Chinese Press. Beijing, China.

13. Cai, Z.Y. (2018) Look at education with freedom. https://yixi.tv/speech/266.

14. Liu, W.J. (2010) My view on Chinese education. China Science and Technology Information, 14: 227-228.

15. Zhang, Y.C. (2017) The capability of education. https://yixi.tv/speech/142.

16. He, Z.S. (2018) City tracker. https://yixi.tv/speech/620.

17. Zallio, M., McGrory, J., Berry, D. (2020) How to democratize Internet of Things devices. A participatory design study to improve digital literacy. arXiv: 2002.06308 